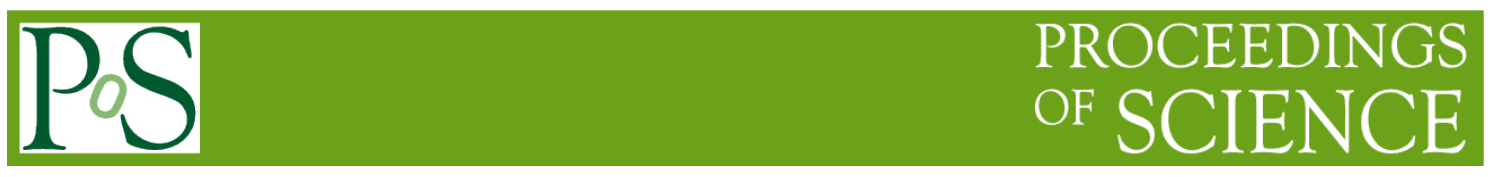

\title{
Coal Mine Lead-acid Battery Intelligent Charger
}

\section{Quanzhu Zhang ${ }^{1}$}

North China Institute of Science and Technology Information and Control Technology Institute Beijing, 101601,China

E-mail:1033803275@qq.com

\section{Hui-fa Qian}

North China Institute of Science and Technology Information and Control Technology Institute Beijing, 101601,China

E-mail:2810429898@qq.com

\section{Yonghong Deng}

North China Institute of Science and Technology Information and Control Technology Institute Beijing, 101601,China

E-mail:309494543@qq.com

For the problems of bulky, low charging efficiency and low input power factor, etc. of traditional charger for mine-used lead-acid battery, a new type of smart charger was developed. The charger, composed of multi-link voltage power units can achieve continuous and adjustable transformation from input three-phase AC voltage with two standards to DC voltage of $0 \sim 300 \mathrm{~V}$ and current of $0 \sim 120 \mathrm{~A}$ through phase shift control of square wave pulse of IGBT inverter. Experimental results show that the charger has achieved three-stage operating mode from constant current to constant voltage and then to the float charging. The voltage and current are relatively stable, the electrolyte density reaction of the battery group is stable without bubbles and the temperature doesn't change obviously in the charging process.

1This work was financially Supported by Hebei Science and Technology Department Project (16274603,16214408), China Coal Industry Association (MTKJ2016-35, MTKJ2016-329). 


\section{Introduction}

The traction power for coal mine locomotives charged with the production of transport tasks is often provided by the lead-acid batteries. The traction power of the battery needs to rely on the charger cycle charge in order to play effectively. At present, the lead-acid battery charging of coal mine adopts the technical scheme of phase-controlled rectification of transformer and thyristor. The scheme features the advantages of large volume, heavy weight, low charging efficiency, low input power factor, large harmonic pollution to the power supply grid and output voltage Ripple. The battery is easy to heat and affect the service life and other shortcomings. In addition, the traditional charger uses the analog circuit control, manual intervention set more intelligent level is low, the lead-acid battery charging process is rough, which may affect the battery life [1-2]. A new type of mine lead-acid battery smart charger was developed herein with small size, light weight, easiness of moving and transportation (especially for the mine chamber charging applications), high charging efficiency, high power factor, the output voltage ripple Small, high degree of intelligence, a variety of voltage formats (such as ground AC380 V, underground AC660 V) General and other advantages.

\section{Intelligent Charger Structure}

The intelligent charger from main circuit (including three-phase full-bridge rectifier circuit, single-phase high-frequency rectifier circuit, high frequency transformer, single-phase full-bridge high-frequency rectifier circuit, LC filter circuit), voltage detection circuit, current detection circuit, display Circuit, control circuit and other components, as shown in Fig. 1.

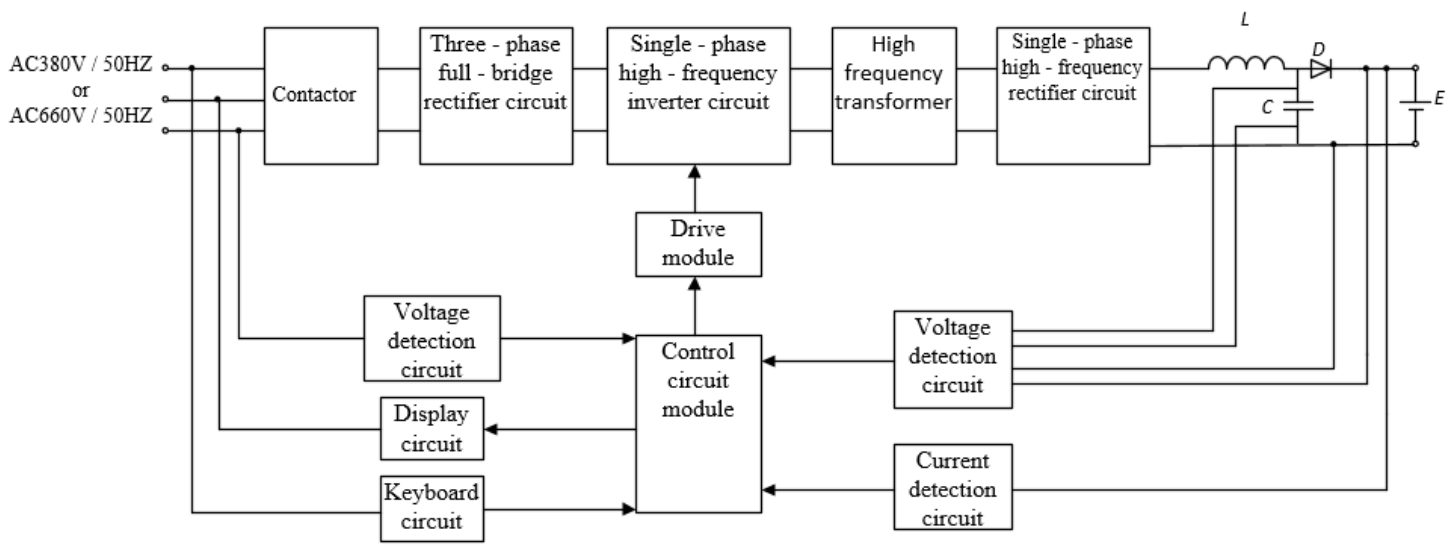

Figure 1: Composition Chart of Intelligent Charger System

\section{Smart Charger Hardware Design}

\subsection{Main Circuit Design}

\subsubsection{Main Circuit and Its Working Principle}

For the smart charger, the main circuit consists of two sets of power converters, as shown in Fig.2. The first-stage $\mathrm{AC} / \mathrm{DC} / \mathrm{AC}_{1}$ power converter principle: input three-phase AC $380 \mathrm{~V} / 50 \mathrm{~Hz}$ or three-phase AC660 V/50 Hz AC frequency sine wave voltage rectified by three-phase uncontrollable diode, get DC510V or DC900V DC voltage; and then through the single-phase IGBT inverter conversion, the amplitude of AC510V/20kHz or AC900V/20kHz 
$\mathrm{AC}$ high frequency square wave voltage. The post-stage $\mathrm{AC}_{2} / \mathrm{DC}$ power converter implements a rectified conversion from an $\mathrm{AC}$ high-frequency square-wave voltage with an input amplitude of $\mathrm{AC} 300 \mathrm{~V} / 20 \mathrm{kHz}$ to a $\mathrm{DC}$ voltage. The transition from $\mathrm{AC}_{1}$ to $\mathrm{AC}_{2}$ is a high-frequency $\mathrm{AC}$ voltage conversion, completed by the high-frequency transformer of the ultra-microcrystalline core to achieve the inverter that generats $20 \mathrm{kHz}$ high frequency square wave voltage step-down conversion, AC510V/20 kHz or AC $900 \mathrm{~V} / 20 \mathrm{kHz}$ AC high frequency square wave voltage stepdown conversion to $\mathrm{AC} 300 \mathrm{~V} / 20 \mathrm{kHz}$ AC high frequency square wave voltage, that is, between the input voltage and the output voltage electrical isolation. The final charge to the lead-acid battery charging voltage is DC0 300V continuously adjustable for different rated voltages, different capacities of the lead-acid batteries and different traction tonnages of the mine electric locomotive.

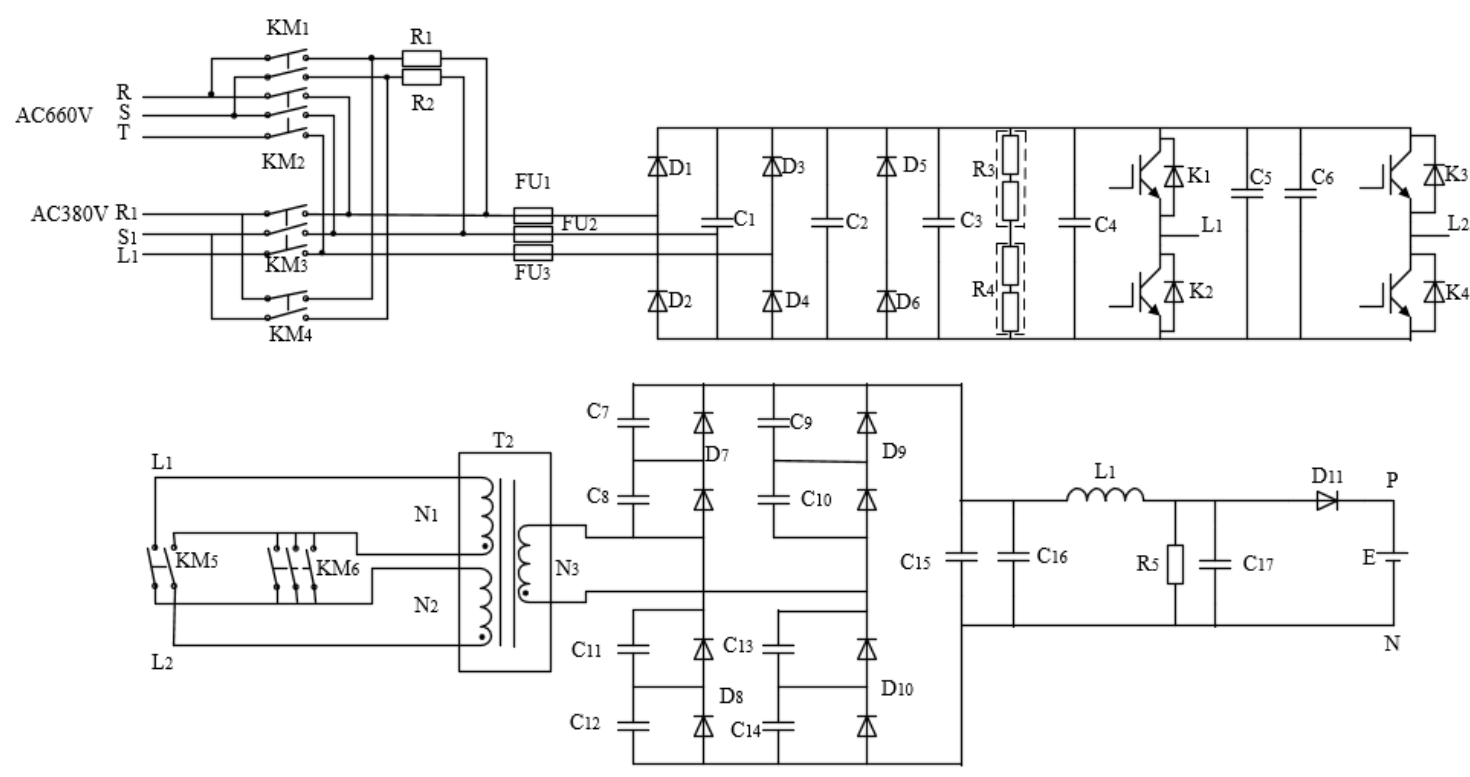

Figure 2:Smart Charger Main Circuit

Continuous adjustment of the output voltage of the main circuit is accomplished by the IGBT single-phase inverter in the first stage power converter and the control mode with constant amplitude width (that is, the amplitude is constant and the pulse width is changed). The primary side of the high-frequency transformer adopts the double-winding $\mathrm{N}_{1}$ and $\mathrm{N}_{2}$ of the double turns. Through the parallel connection of the two sets of windings, the series connection is used to realize the effective switching of the input voltage. The series-parallel switching of the winding is controlled by two interlocking Contactor $\mathrm{KM}_{5}$ and $\mathrm{KM}_{6}$. When $\mathrm{KM}_{5}$ is closed and $\mathrm{KM}_{6}$ is off, the winding $\mathrm{N}_{1}$ is connected in parallel with $\mathrm{N}_{2}$. This method is suitable for the input voltage AC380 V. When $\mathrm{KM}_{6}$ is closed and $\mathrm{KM}_{5}$ is off, the winding $\mathrm{N}_{1}$ is connected in series with $\mathrm{N}_{2}$. This method is suitable for the input voltage AC660 V.

According to the principle of transformer operation, the core volume of the transformer is inversely proportional to the frequency of the input $\mathrm{AC}$ voltage. Therefore, the input voltage of the transformer in the charger is $20 \mathrm{kHz}$ high-frequency $\mathrm{AC}$ square wave voltage with ultrasmall size and weight of the transformer.

\subsubsection{Case Analysis}

Taking the input voltage system of three-phase AC380V/50Hz ground as an example, the 
operation principle of intelligent charger is explained. When the $\mathrm{KM}_{3}$ contactor $\left(\mathrm{KM}_{2}\right.$ interlock disconnect) is closed, the AC/DC rectification is realized by the rectifier bridge composed of $\mathrm{D}_{1} \sim \mathrm{D}_{6}$, and the supporting capacitor $\mathrm{C}_{4}$ is charged to establish the DC510V voltage. Before $\mathrm{KM}_{3}$ is closed, $\mathrm{KM}_{4}$ will be closed for a short time $\left(\mathrm{KM}_{2}\right.$ interlocked) to limit the charge current to capacitor $\mathrm{C}_{4}$. Once the $\mathrm{DC}$ voltage is close to build up, $\mathrm{KM}_{4}$ will get disconnected automatically by the $\mathrm{KM}_{3}$ to complete the power supply. The series resistors $\mathrm{R}_{3}$ and $\mathrm{R}_{4}$ provide the discharge path for the sustaining capacitor $\mathrm{C}_{4}$, and the capacitors $\mathrm{C}_{1}$ to $\mathrm{C}_{3}$ are connected in parallel to the bridge arm consisting of two rectifier diodes in series. The absorption line leakage inductance causes a spike caused by the commutation of the device Voltage. DC voltage through the IGBTK $_{1} \sim \mathrm{K}_{4}$; with the single-phase inverter, the DC voltage into a single-phase high-frequency $\mathrm{AC}$ square wave voltage $\mathrm{AC} 510 \mathrm{~V} / 20 \mathrm{kHz}$ to achieve the first level $\mathrm{AC} / \mathrm{DC} / \mathrm{AC}_{1}$ transformation.

High-frequency transformer completes the step-down isolation conversion, AC510V/20kHz AC square wave into AC300V/20kHz by controlling the inverter IGBT conduction phase angle control inverter output voltage, 0 to $300 \mathrm{~V}$. The capacitor $\mathrm{L}$ also protects the IGBT's overvoltage absorption circuit. The high frequency AC square wave voltage is rectified by a single-phase rectifier bridge consisting of a second-stage fast diode (reverse recovery time less than $20 \mathrm{~ns}) \mathrm{D}_{7}$ to $\mathrm{D}_{10} .0 \sim 300 \mathrm{~V}$ continuously adjustable DC voltage, and then through the high-frequency inductance $\mathrm{L}_{1}$ and electrolytic capacitor $\mathrm{C}_{17}$ composed of LC filter circuit, and finally through the diode $\mathrm{D}_{11}$ output to the lead-acid battery pack.

Two fast rectifier diodes are connected in series to increase the withstand voltage to accommodate high voltage (AC660 V) input. $\mathrm{C}_{7} \sim \mathrm{C}_{14}$ for the fast diode pressure and absorption of high frequency voltage spikes in order to protect the fast diode. The output side of the diode $D_{11}$ role: (1) to prevent the battery positive and negative when the reverse (wrong load) and rectifier bridge constitute a short circuit; (2) the charger output voltage and battery voltage separated, the two voltage Value as a feedback value (shown in Fig. 1) in order to achieve the charger constant voltage, the constant current mode of operation control.

The single-phase inverter power device selection FF300R17ME4 IGBT, the maximum collector current $\mathrm{I}_{\mathrm{C}}=300 \mathrm{~A}$, the maximum collector between the voltage UCES $=1700 \mathrm{~V}$, the internal integration of the NTC temperature sensor, suitable to the switching frequency of 15 $30 \mathrm{kHz}$. The IGBT power tube drives the module selection 2SP0115T2Ax. The drive module is simple to be used, highlights reliable operation, short circuit protection with input voltage monitoring and isolation voltage.

\subsection{Control Circuit Design}

\subsubsection{Control Structure}

The smart charger to complete the voltage (current) control circuit is IGBT single-phase inverter. The control circuit of IGBT single-phase inverter is composed of UC3875 chip and SPMC75F2413A single chip microcomputer. UC3875 is a phase-shifted resonant PWM controller for generating four PWM control signals while achieving the closed-loop control of the output voltage[3]. As SPMC75F2413A microcontroller is an industrial 16-bit microcontroller, its hardware resources are very rich, with $80 \mathrm{I} / \mathrm{O}$ pins, internal integration of the PLL, watchdog, serial communication, 10-bit AD conversion circuit. The single-chip microcomputer is used to realize the operation and management of the control system, the data acquisition and display, the closed-loop control of the charging current and the selection of constant voltage and constant current control. IGBT single-phase inverter control structure is 
shown in Fig. 3. The charger is set with the output voltage $U_{\mathrm{Dg}}$ and the output current $\mathrm{I}_{\mathrm{g}} 2$ set point. The output of the single-phase high-frequency rectifier circuit (both ends of the capacitor $\mathrm{C} 17)$ is converted by the voltage detection and adjustment circuit to obtain the voltage feedback value $U_{f}$. The current $I_{\text {out }}$ flowing through the battery pack $E$ is subjected to the current detection and the conditioning circuit to obtain the current feedback value. If The $\mathrm{U}_{\mathrm{dG}}$ and Ig are input to the single-chip sampling, the microcontroller gets the current control given signal UIG through the PI regulator operation. For the voltage closed loop selection algorithm $F(u)$, when $U_{d G}>U_{f}$, $\mathrm{U}_{\text {out }}=\mathrm{U}_{\mathrm{IG}}$; when $\mathrm{U}_{\mathrm{dG}}=\mathrm{U}_{\mathrm{f}}, \mathrm{U}_{\text {out }}=\mathrm{U}_{\mathrm{dG}}$. This will achieve the voltage closed-loop and the current closed-loop effective combination and conversion, the charger constant voltage and constant current control, constant current charging to constant voltage floating automatic conversion. The voltage closed-loop control is achieved by the UC3875 hardware PI regulator circuit.

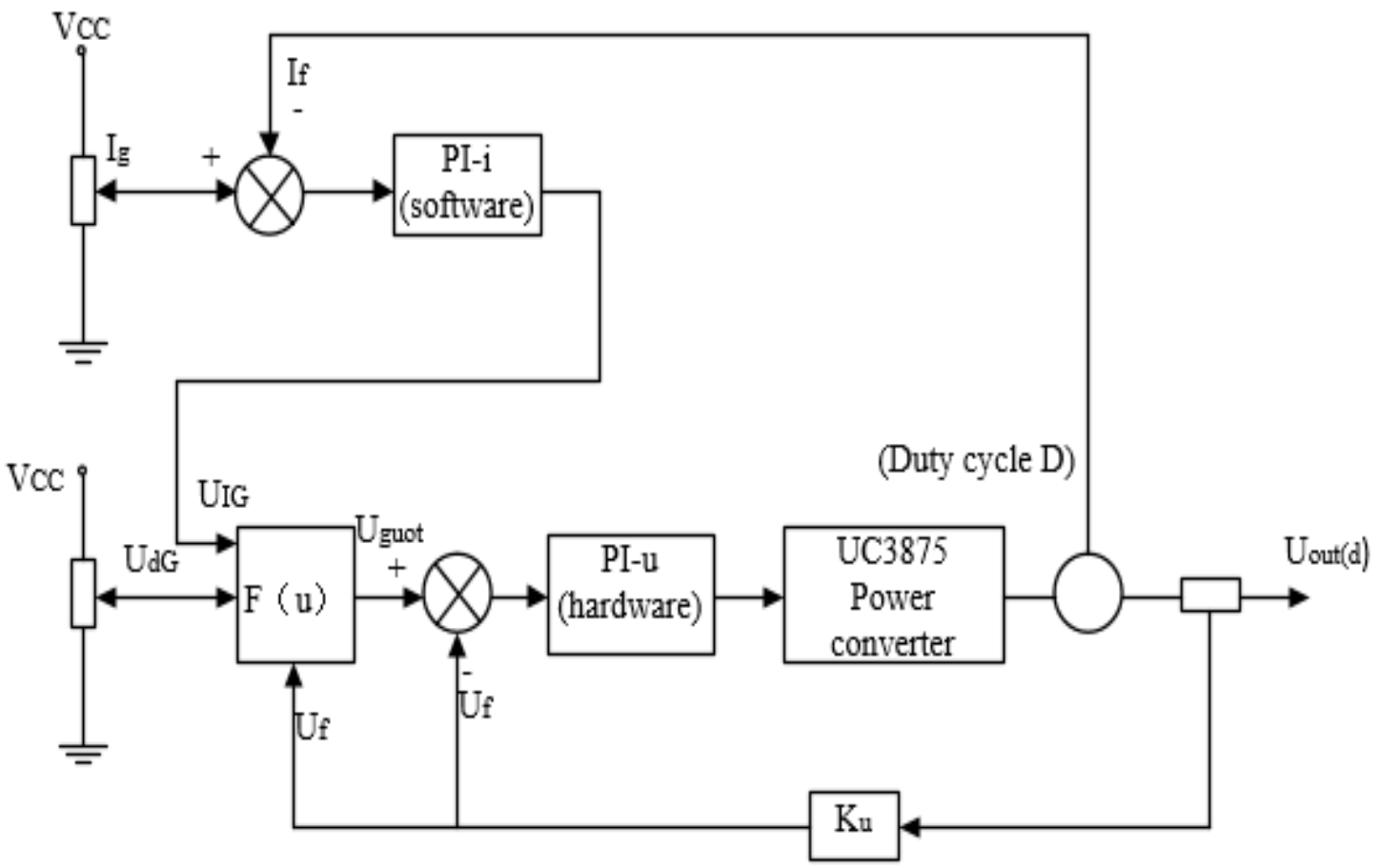

Figure 3:IGBT Single Phase Inverter Control Structure

\subsubsection{Control Circuit}

UC3875 chip has 2 pairs and 4 independent PWM waves to output circuit. OUTA and OUTB output two opposite phases of the PWM wave, and the dead time t1 can be adjusted; OUTC and OUTD also output two opposite phases of PWM wave, and the dead time $t_{2}$ can also be adjusted. Dead times $t 1$ and $t_{2}$ are mutually independent. UC3875 chip with a simple external circuit, drive current and duty cycle can be adjusted in the range of $0 \sim 100 \%$, stable, etc. [4]. 


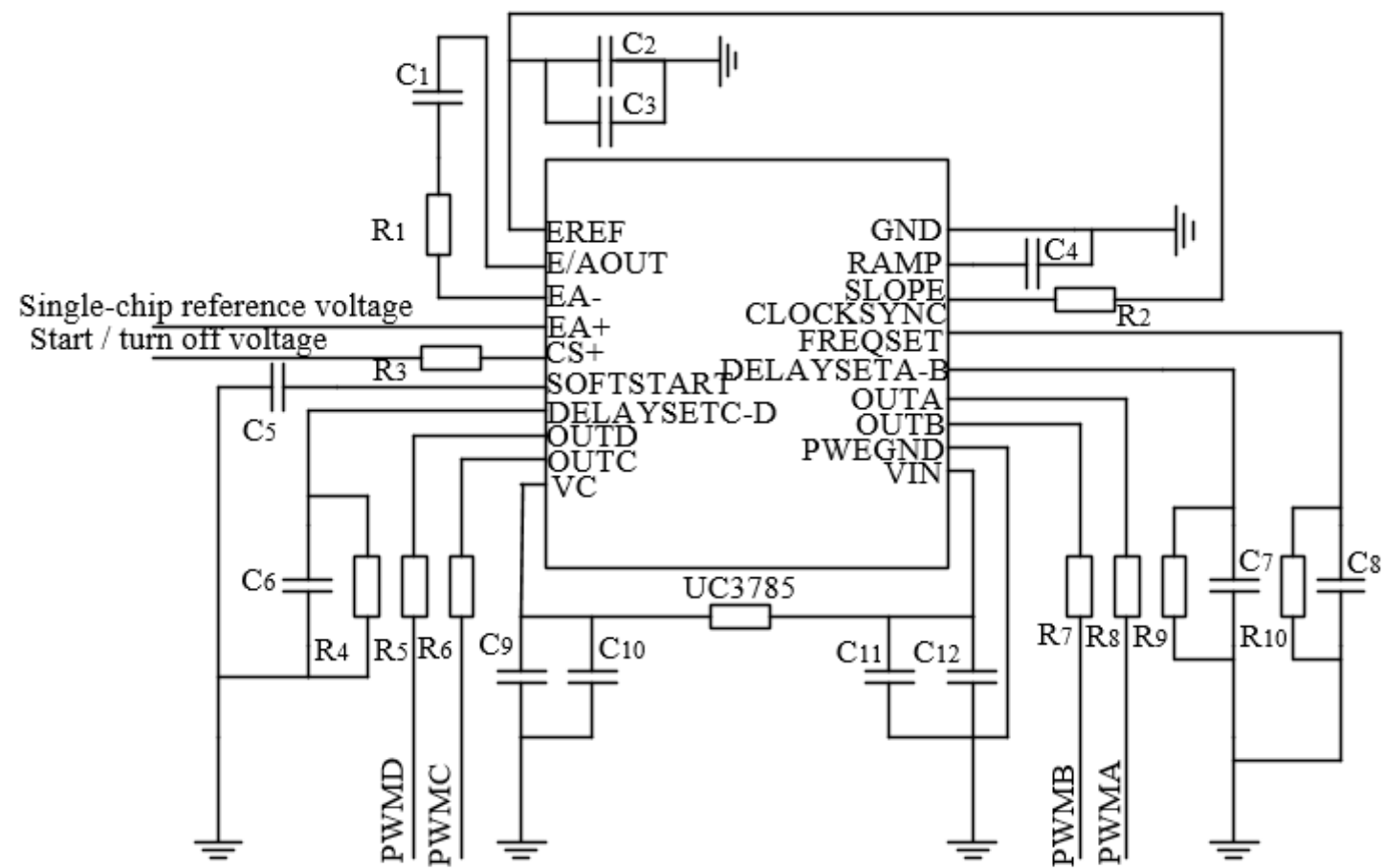

Figure 4:Inverter Control Circuit

The inverter control circuit is shown in Figure. The output voltage $U_{\text {out }}$ of the single-phase high-frequency rectifier circuit is converted to the EA-terminal of the UC3875 via voltage detection conditioning and the voltage feedback signal $U_{\mathrm{f}}$ together with the $\mathrm{U}_{\text {gout }}$ (possibly UIG (or $\mathrm{U}_{\mathrm{dG}}$ ) input from the $\mathrm{EA}+$ terminal to form a feedback closed-loop control circuit. The dynamic parameters of the PI regulator depend on the circuit parameters $R_{1}$ and $C_{1}$. The UC3875 also sets the overcurrent lock circuit and the soft-start circuit, etc. When the CS+ terminal (constant voltage) or the constant current control to the low level, then output PWM wave; when the CS+ side to high, UC3875 overcurrent protection, it will prohibit the output of PWM wave. If the soft start function by the external capacitor $\mathrm{C}_{5}$ is to achieve greater the capacitance value, the longer the start time will be. $C_{6}, R_{4}$ and $C_{7}, R_{9}$ values determine the PWM pulse control signal dead time $\mathrm{C}_{8}$ and $\mathrm{R}_{10}$ value determines the PWM pulse control signal frequency. OUTA, OUTS, OUTC, OUTD output 4 PWM pulse signals driven by the drive circuit Single-phase inverter 4 IGBT operation [5-7].

\section{Intelligent Charger Software Design}

The intelligent charger software program includes the main program, the input voltage system selection subroutine, the current PI regulator algorithm subroutine, the interrupt service subroutine and the timer interrupt service routine. The main program completes the main function registers and I/O port initialization, RS232 serial communication while displaying module initialization. See Fig. 5 (a) below for the process. The timer interrupt service routine mainly completes the sampling and filtering of the given and detected variables. The current PI regulator algorithm subroutine achieves the adjustment operation of main PI. The PI adjustment parameters can be set very easily to ensure the stability and fastness of the closed-loop control. See Fig. 5 (b) below for the process. The input voltage system selection subroutine completes the input voltage standard (ground AC380V or downhole AC660V) selection, drives the 
corresponding input contactor disconnect and close, contactor interlock and other functions. See Fig. 5(c) for the process.

\section{Experimental Results and Analysis}

Smart charger has constant-voltage charging, constant-current charging, two- stage charging, three-stage charging and other charging mode, in addition to these, there are 2 ways of work: manual intervention charging, fully automatic charging. The automatic charging method includes two-stage constant current constant voltage and three-stage constant current constant voltage. The working mode of the charger can be set and operated by the panel operation keyboard and switch; the charging mode can be realized by setting the corresponding function code parameters by operating the keyboard. The operation of the entire charger and parameter settings are very flexible and convenient. In the coal mine ground and underground on the smart charger experiments, see Fig. 6 for the high-frequency transformer of different switching frequencies and output voltage of the high-frequency AC PWM waveform..

In the coal mine experimental operation, the charger uses three-stage constant current constant pressure float charge automatic charging, which is commonly used in a coal charging method. In comparison with other charging methods, it is more conducive to extend the battery life but long charging time. For the commonly used $8 \mathrm{t}$ mine electric locomotive lead-acid battery pack, with a smart charger to charge, set the charging voltage of $176 \mathrm{~V}$, charging current of $60 \mathrm{~A}$ and the experimental data in Table 1. The experimental results show that the smart charger is capable of achieving a good constant current to constant pressure and then floating the three-stage mode of operation, charging current with stable voltage, smooth charging process battery electrolyte density response and no bubbles. The temperature didn't change significantly[8].
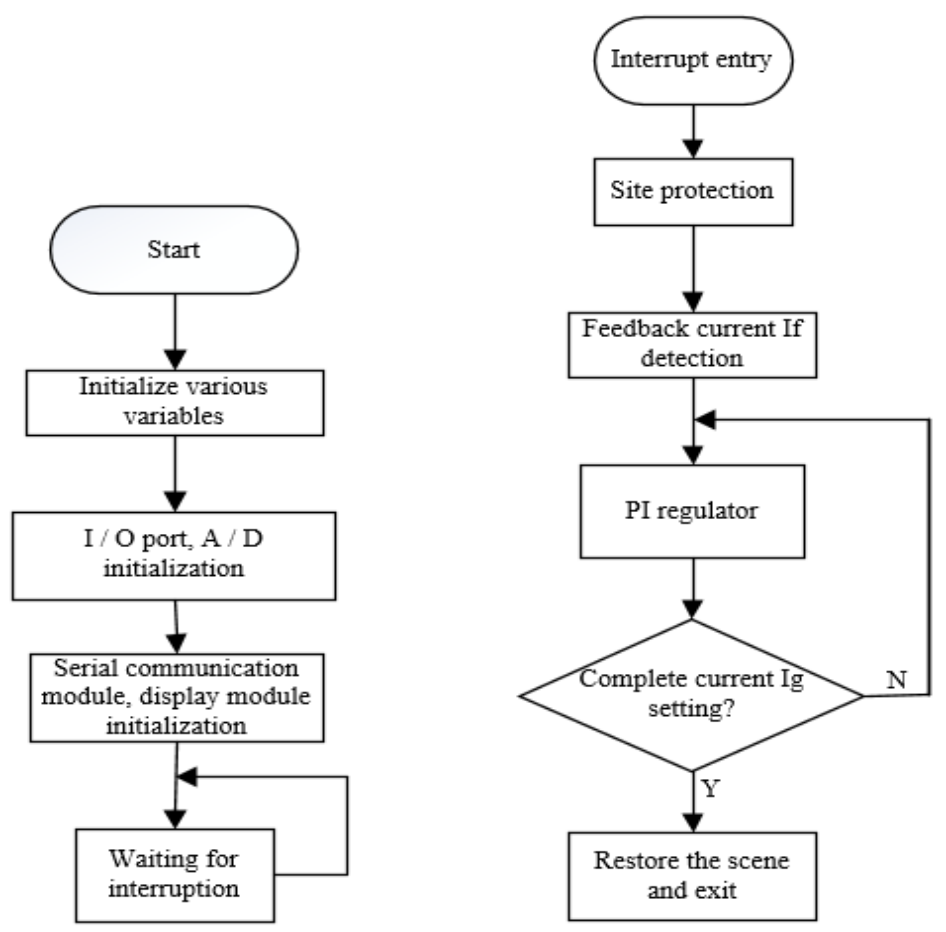

(a) Main Program Flow (b) Current PI Regulator Algorithm Subroutine Flow 


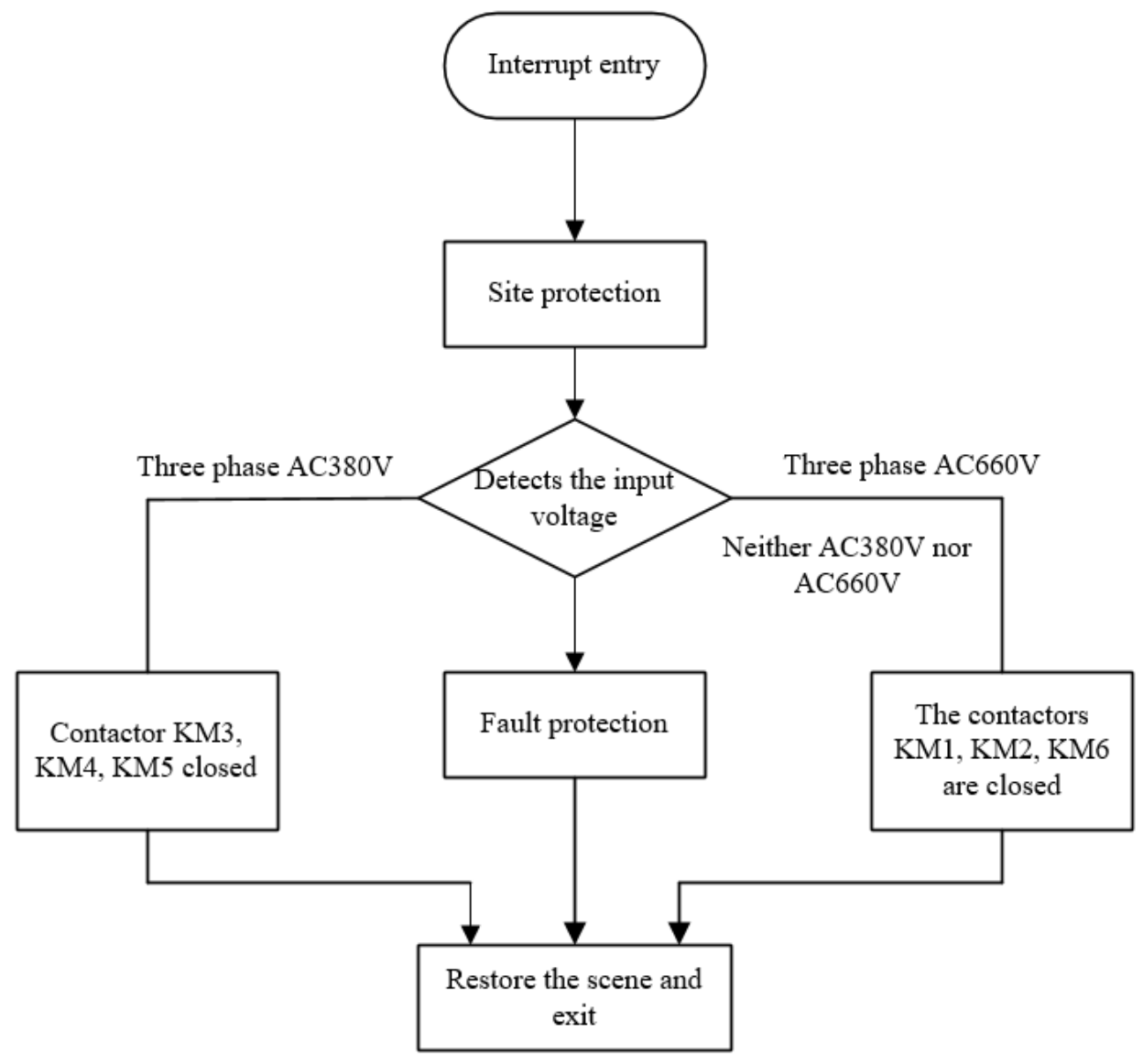

(c)The input voltage system selects the subroutine flow

Figure 5:Smart Charger Software Flow
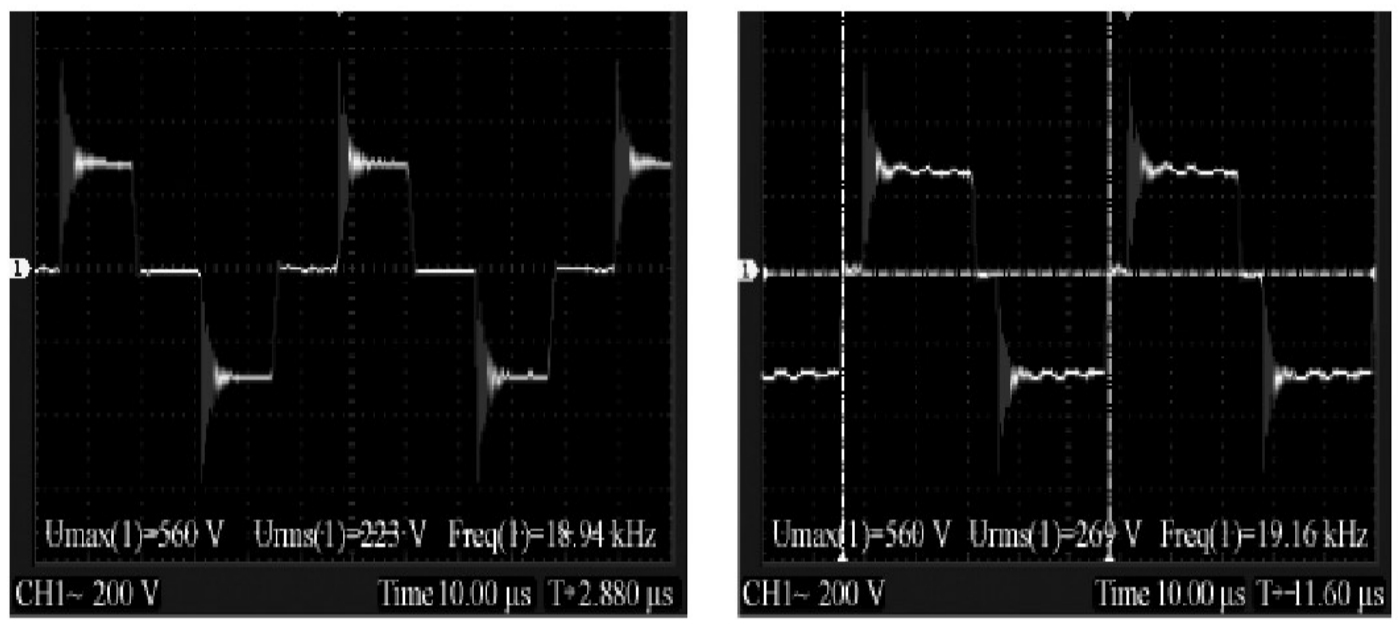

(a)waveforms at different switching frequencies (b) waveforms at different output voltages Figure 6:High Frequency AC PWM Wave 


\begin{tabular}{cccc||cccc}
\hline $\begin{array}{c}\text { Charge Charge } \\
\text { Time } \\
\text { /h }\end{array}$ & $\begin{array}{c}\text { Coltage } \\
\text { /V }\end{array}$ & $\begin{array}{c}\text { Current } \\
\text { /A }\end{array}$ & $\begin{array}{c}\text { Electrolyte } \\
\text { Density } \\
\text { /(kg.L-1) }\end{array}$ & $\begin{array}{c}\text { Charge } \\
\text { Time } \\
/ \mathrm{h}\end{array}$ & $\begin{array}{c}\text { Charge } \\
\text { Voltage } \\
/ \mathrm{V}\end{array}$ & $\begin{array}{c}\text { Charge } \\
\text { Current } \\
/ \mathrm{A}\end{array}$ & $\begin{array}{c}\text { Electrolyte } \\
\text { Density } \\
/(\mathrm{kg} . \mathrm{L}-1)\end{array}$ \\
\hline 1 & 157 & 60 & 1.17 & 9 & 171 & 40 & 1.23 \\
2 & 159 & 60 & 1.19 & 10 & 172 & 40 & 1.24 \\
3 & 160 & 60 & 1.19 & 11 & 174 & 40 & 1.25 \\
4 & 161 & 60 & 1.19 & 12 & 175 & 10 & 1.27 \\
5 & 163 & 60 & 1.21 & 13 & 176 & 10 & 1.28 \\
6 & 164 & 60 & 1.21 & 14 & 176 & 10 & 1.28 \\
7 & 167 & 60 & 1.23 & 15 & 176 & 0 & 1.28 \\
8 & 169 & 60 & 1.23 & & & & \\
\hline
\end{tabular}

Table 1: Experimental Data of the Charger Operation

\section{Conclusion}

The intelligent charger is designed in this paper, Its main circuit is based on the IGBT power device and the super crystal core high-frequency transformer, Its control circuit is based on SPMC75F2413A microcontroller and 3875PWM chip. As the smart charger features small and lightweight, great intelligence, suitability for a variety of coal mine voltage systems. It can help extend the battery's use life and other characteristics, in particular, its output voltage and continuously adjustable current range, basically covering all the motor car's battery specifications and types, can fully adapt to the coal mine ground, two different voltage systems underground; besides, as its versatility is very strong, it features sound application value in the field of coal.

\section{References}

[1] wang zhao an,huang jun.Power Electronics Technology[M].Through version. beijing :Mechanical Industry Press, 2007.

[2] Zhang Zhansong,Cai Xuan three.Switching power supply principle and design [M]. Beijing: Electronic Industry Press, 1998.

[3] BOSEBK. Modern power electronics and communication drive [M]. Wang Cong, Zhao Jin, Yu Qingguang translation. Beijing: Mechanical Industry Press, 2005.

[4] Wang Zhaonian, Zhang Mingxun. Power electronic equipment design and application manual [M]. Beijing: Mechanical Industry Press, 2002.

[5] Pan Yuchen, Ma Zhiquan, etc.. Lead-acid battery smart charger [J]. Journal of Quanzhou Normal University, 2016 (4): 34-2. 
[6] Li Weibing, Zhang Zhichao, et al. Design of "Electric Vehicle" Intelligent Charger [J]. Manufacturing Automation, 2012 (2): 34-2.

[7] Li Chengqian, Zhou Ke, et al. Design of battery charger based on AVR microcontrollers [J]. Industrial Control Computer, 2016: 29-9.

[8] Lei Yuanlin, Huang Yuanfeng, etc .. An electric vehicle battery smart charger design [J]. Electronic Design Engineering, 2013 (12): 21-24. 